\title{
Controlled weather balloon ascents and descents for atmospheric research and climate monitoring
}

\author{
Andreas Kräuchi ${ }^{1}$, Rolf Philipona ${ }^{2}$, Gonzague Romanens ${ }^{2}$, Dale F. Hurst ${ }^{3,4}$, Emrys G. Hall ${ }^{3,4}$, and Allen F. Jordan ${ }^{3,4}$ \\ ${ }^{1}$ Institute for Atmospheric and Climate Science, ETH Zurich, 8057 Zurich, Switzerland \\ ${ }^{2}$ Federal Office of Meteorology and Climatology MeteoSwiss, Aerological Station, 1530 Payerne, Switzerland \\ ${ }^{3}$ Cooperative Institute for Research in Environmental Sciences, University of Colorado, Boulder, Colorado 80309, USA \\ ${ }^{4}$ NOAA Earth System Research Laboratory, Global Monitoring Division, Boulder, Colorado 80305, USA
}

Correspondence to: Rolf Philipona (rolf.philipona@meteoswiss.ch)

Received: 9 September 2015 - Published in Atmos. Meas. Tech. Discuss.: 3 December 2015

Revised: 17 February 2016 - Accepted: 18 February 2016 - Published: 7 March 2016

\begin{abstract}
In situ upper-air measurements are often made with instruments attached to weather balloons launched at the surface and lifted into the stratosphere. Present-day balloonborne sensors allow near-continuous measurements from the Earth's surface to about $35 \mathrm{~km}(3-5 \mathrm{hPa})$, where the balloons burst and their instrument payloads descend with parachutes. It has been demonstrated that ascending weather balloons can perturb the air measured by very sensitive humidity and temperature sensors trailing behind them, particularly in the upper troposphere and lower stratosphere (UTLS). The use of controlled balloon descent for such measurements has therefore been investigated and is described here. We distinguish between the single balloon technique that uses a simple automatic valve system to release helium from the balloon at a preset ambient pressure, and the double balloon technique that uses a carrier balloon to lift the payload and a parachute balloon to control the descent of instruments after the carrier balloon is released at preset altitude. The automatic valve technique has been used for several decades for water vapor soundings with frost point hygrometers, whereas the double balloon technique has recently been re-established and deployed to measure radiation and temperature profiles through the atmosphere. Double balloon soundings also strongly reduce pendulum motion of the payload, stabilizing radiation instruments during ascent. We present the flight characteristics of these two ballooning techniques and compare the quality of temperature and humidity measurements made during ascent and descent.
\end{abstract}

\section{Introduction}

Weather balloons have been used for climate and meteorological research for more than 100 years. The first instrumented, unmanned "free" balloon was launched by Gustave Hermite in 1892. His waxed-paper balloon, inflated with illuminating gas (mostly hydrogen and methane), carried a minimum-registering mercury barometer (Hermite, 1892). This was in effect the birth of balloon-borne measurements for scientific studies of the atmosphere. In about 1900, Richard Assmann in Berlin increased the height ceiling of soundings by introducing a closed rubber balloon to replace those of paper, silk or goldbeater's skin (Hoinka, 1997). Sounding balloons enabled the discovery of the tropopause (Teisserenc de Bort, 1902) and became a standard tool for atmospheric measurements and meteorological weather prediction. Instruments that send data from balloons to the ground using small radio frequency transmitters, now commonly known as radiosondes, were invented by Robert $\mathrm{Bu}$ reau in France in 1929. Some radiosondes are now capable of capturing and transmitting data from other balloon-borne instruments, greatly expanding the measurement capabilities of balloon payloads.

With strong evidence of climate change and a refined knowledge that atmospheric composition in the upper troposphere and lower stratosphere (UTLS) plays an important role in radiative effects in Earth's climate system (Forster and Shine, 2002; Solomon et al., 2010), upper-air in situ and remote sensing observations for climate have been given more attention in recent years because so few exist. The 35 -year 
frost point hygrometer (FPH) record of NOAA's Earth System Research Laboratory (ESRL) at Boulder, Colorado $\left(40^{\circ}\right.$, $105^{\circ} \mathrm{W}$ ), shows the significant variability of UTLS water vapor on interannual and longer timescales (Hurst et al., 2011). However, this long data record is limited to only one location in the northern midlatitudes and should not be used to assess global trends. The Global Climate Observing System (GCOS) Reference Upper Air Network (GRUAN) is designed to produce long-term, climate-quality records of essential climate variables in the troposphere and stratosphere (Trenberth et al., 2002; GCOS-112, 2007; Seidel et al., 2009; Bodeker et al., 2016) at 20-30 globally distributed sites. Primary objectives of GRUAN are to monitor changes in temperature and water vapor profiles in the lower troposphere and the UTLS (Thorne et al., 2005; Randel et al., 2006).

Here we describe two novel ballooning techniques that allow instruments to make high-quality measurements while ascending and descending at similar controlled rates of speed. The main reasons for controlled ballooning are to prevent pendulum motions during ascent, to measure clean, unperturbed air during descent at speeds similar to ascent and to obtain two vertical profiles at slightly different locations and times with a single balloon launch. The first method uses one balloon and a simple automatic valve to release helium from the balloon once it reaches a preset ambient pressure. This method has been used successfully for FPH soundings since the mid-1960s, first by the Naval Research Laboratory in Washington D.C. (Mastenbrook, 1966), then by the NOAA ESRL in Boulder. The other method uses a double balloon technique that was first utilized by Hugo Hergesell in collaboration with the Prince of Monaco in 1905 over the Mediterranean Sea (Hergesell, 1906). The double balloon technique uses a large and small balloon to lift the instruments and control the descent rate, respectively. This technique has recently been revived to measure the radiation budget through the atmosphere (Philipona et al., 2012), where a stable pendulumfree ascent is required to keep the instruments as horizontal as possible. The double balloon method also allows highquality measurements to be made during controlled descent. In the following we also discuss in detail the contamination problems of ascent measurements, demonstrate some advantages and disadvantages of controlled ascent and descent measurements and compare temperature and humidity profiles obtained during traditional (burst) and controlled descents.

\section{Traditional ballooning and associated problems}

Balloon-borne experiments are the backbone for in situ vertical profile measurements of pressure, temperature, humidity, ozone and horizontal winds in the troposphere and stratosphere. Traditional meteorological radio soundings, long employed by national weather services, start with ascent at a fairly steady vertical velocity of $5 \mathrm{~m} \mathrm{~s}^{-1}$ up to the al-

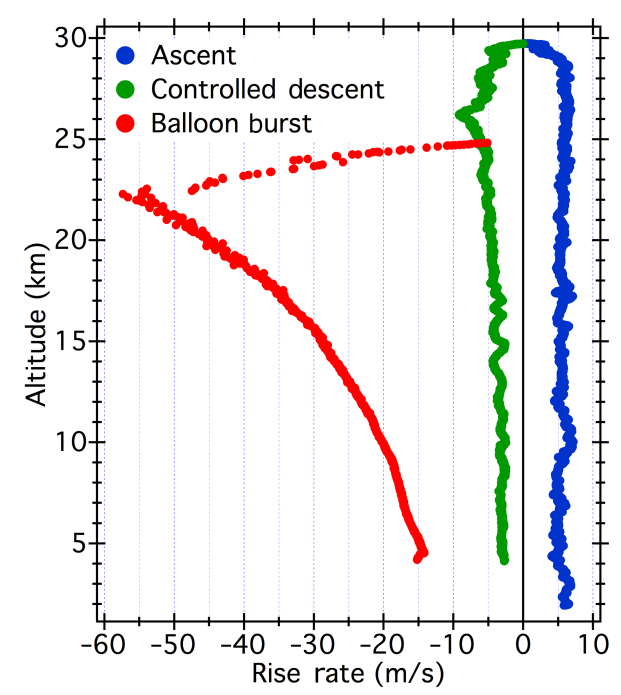

Figure 1. Typical balloon vertical velocities during ascent (blue) followed by controlled descent using the automatic valve method (green) or descent after balloon burst (red). The ascent profile shows the valve opened at $28.5 \mathrm{~km}$, first reducing the ascent rate to zero (float) then establishing a slow and fairly steady descent rate $<10 \mathrm{~m} \mathrm{~s}^{-1}$ (green). The red profile indicates the balloon burst prematurely at $25 \mathrm{~km}$, prior to activation of the valve. The descent rate after burst initially exceeded $50 \mathrm{~m} \mathrm{~s}^{-1}$ then was gradually slowed to $<20 \mathrm{~m} \mathrm{~s}^{-1}$ by the parachute. For both descent profiles reception of the radiosonde telemetry signal was lost at $\sim 4 \mathrm{~km}$.

titude of balloon burst (typically $\sim 35 \mathrm{~km}$ ). After balloon burst the payload falls at high speed $\left(40-60 \mathrm{~m} \mathrm{~s}^{-1}\right)$ to about $20 \mathrm{~km}$, where the parachute begins to reduce the rate of descent to $<40 \mathrm{~m} \mathrm{~s}^{-1}$ (Fig. 1). Below $10 \mathrm{~km}$ altitude the descent rate slows to $<20 \mathrm{~m} \mathrm{~s}^{-1}$ if the parachute functions correctly and the payload eventually impacts the surface at 5$15 \mathrm{~m} \mathrm{~s}^{-1}$. This uncontrolled, high-velocity descent significantly reduces the vertical resolution of measurements and is often detrimental to the quality of measurements. Almost all balloon soundings are performed in this traditional way and, consequently, only the ascent data are considered useful. Some very sensitive and fast response humidity sensors affected by contamination during ascent have measured quite successfully during the high-speed descent after balloon burst of traditional balloon flights (Lykov et al., 2009), but for many instruments, their performance is worse during rapid free fall through the stratosphere.

Some specific problems are associated with the exclusive use of ascent measurements of temperature and humidity for climate research. Especially in the UTLS, ascent measurements are prone to contamination by the balloon and flight train that lead the sensor payload. Sensors with high sensitivities and rapid response times are also susceptible to the pendulum motion of the payload that moves sensors in and out of the balloon's wake. 


\subsection{Temperature measurement contamination}

Instrument payloads are typically suspended $30-50 \mathrm{~m}$ below the balloon by a tether string. During the balloon ascent, the gas inside expands adiabatically if there is no heat exchange with the surrounding air. Within the troposphere this cooling of the balloon gas closely tracks the near-adiabatic temperature gradient of the external air. Above the tropopause, where temperature generally increases with height, the balloon gas continues to cool adiabatically but is also heated by the warmer external air. During nighttime this heat transfer cools the air that touches the balloon skin by several degrees, while keeping the temperature of the balloon gas close to the external temperature. During daytime the direction of heat transfer is reversed because solar radiation strongly heats the balloon skin and gas, overpowering the adiabatic cooling of the balloon gas. In both cases the temperature of the air stream that comes in contact with the balloon is altered by heat exchange with the balloon gas (Tiefenau and Gebbeken, 1989; Shimizu and Hasebe, 2010). Temperatures measured in the wake of the balloon (i.e., during ascent) are thus artificially cool and warm during nighttime and daytime, respectively. Due to the pendulum motion of the tethered instrument payload these artifacts are often observed as short-term negative and positive temperature spikes. Both effects grow with decreasing pressure hence their influences increase with height.

Figure 2 shows temperature profiles measured by the very fast-response thermocouple sensor of a Meteolabor SRS-C34 radiosonde and the adverse effects of the nighttime cooling and daytime heating of air that touched the balloon skin just prior to reaching the sensor. Nighttime measurements above $31 \mathrm{~km}$ show sharp cold spikes of several degrees while daytime spikes are positive and equally as large. The contamination is manifested as spikes in the measurements because the sensor swings in and out of wake of the balloon. The spikes represent large measurement errors that greatly exceed the $2 \%$ precision and accuracy limits prescribed by GRUAN (GCOS-112, 2007).

\subsection{Humidity measurement contamination}

Influences on humidity measurements in the wake of a balloon during ascent are related to the numbers and types of clouds the balloon passes through and the overall moisture content of the tropospheric column. Moisture that is collected on the balloon skin and flight train outgasses continuously during flights, but the effect is especially significant in the extremely dry stratosphere. The high-sensitivity hygrometers developed for UTLS water vapor measurements easily measure this contamination during balloon ascent (Vömel et al., 2007; Lykov et al., 2009; Hurst et al., 2011). While the balloon contamination of temperature measurements during ascent can often be reduced with a longer payload tether string, the adverse effects of water vapor outgassing are far more
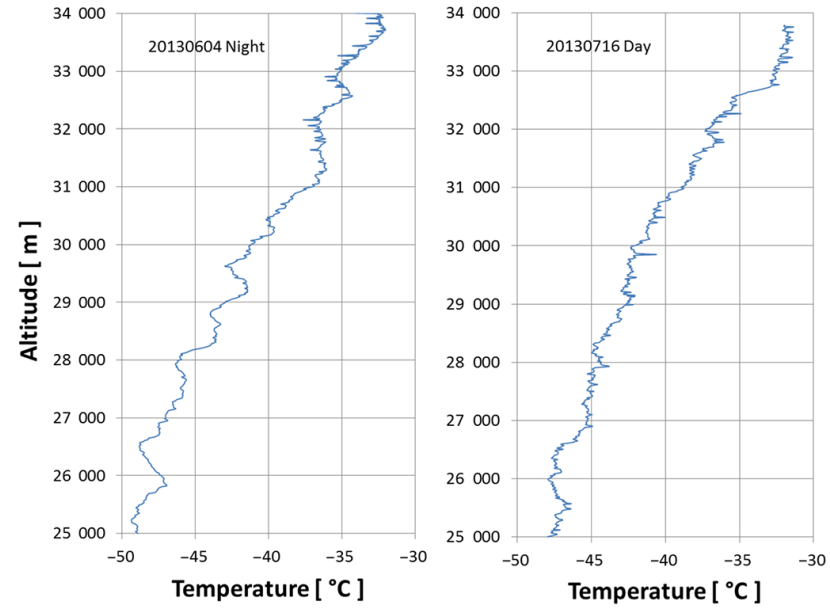

Figure 2. Stratospheric temperature profiles measured from ascending balloons during nighttime (left panel) and daytime (right panel) with a Meteolabor SRS-C34 radiosonde. The nighttime profile exhibits negative temperature spikes above $31 \mathrm{~km}$, while the daytime profile shows positive spikes above $25 \mathrm{~km}$. Both ascent profiles are affected by the exchange of heat between the balloon gas and the external air that was in contact with the balloon skin just prior to reaching the temperature sensor.

difficult to overcome, especially in very dry regions of the atmosphere.

FPH soundings by the Global Monitoring Division of NOAA ESRL often show intermittent water vapor measurement contamination during balloon ascent, especially when balloons are launched in cloudy conditions. Persistent ascent measurement contamination starting $\sim 8 \mathrm{~km}$ above the tropopause is a typical feature of FPH humidity profiles because temperature and solar irradiance increase with altitude above the tropopause, warming the balloon skin and intensifying outgassing (Fig. 3). In uncontaminated conditions the performance of the FPH during ascent and descent is similar because the direction of sample flow through the instrument is irrelevant (i.e., the air intake and exhaust paths are identical). For these reasons FPH measurements made during controlled descent are preferable to ascent measurements in the UTLS. The high-resolution controlled descent data can be used to identify and flag ascent measurements affected by contamination, especially in the UTLS. In contrast, FPH measurements made after balloon burst, as the payload falls at $>20 \mathrm{~m} \mathrm{~s}^{-1}$ through the stratosphere, are of lower vertical resolution and typically poorer quality than the ascent data, making them less useful in identifying contaminated ascent measurements.

\section{Novel ballooning techniques}

The contamination of temperature and humidity measurements during balloon ascent makes it desirable to utilize con- 


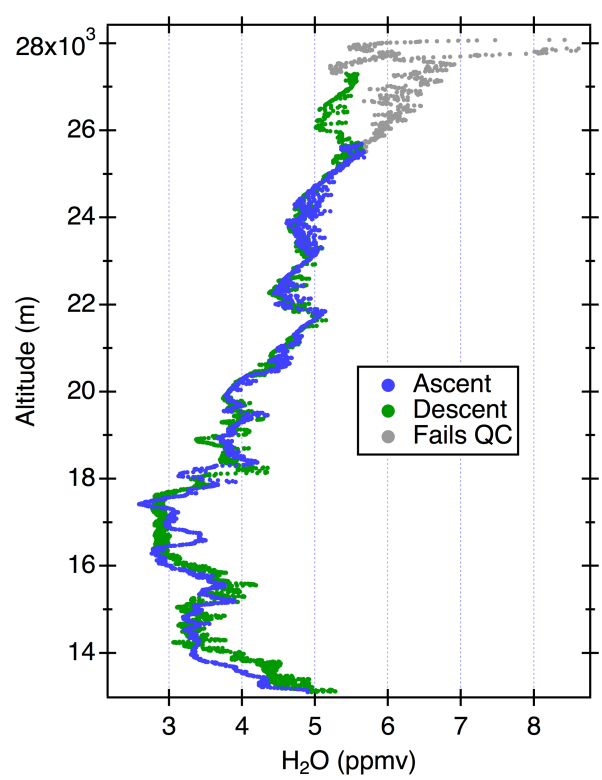

Figure 3. Stratospheric water vapor mixing ratio profiles measured by the NOAA FPH during balloon ascent (blue) and controlled descent (green) over Boulder, Colorado. The two profiles are similar except above $25.5 \mathrm{~km}$ where the ascent measurements become contaminated by the persistent outgassing of moisture from the balloon and flight train. High-quality, uncontaminated FPH measurements (those passing quality control) resume during controlled descent at $\sim 27 \mathrm{~km}$, approximately $1 \mathrm{~km}$ below the altitude of balloon turnaround (float).

trolled descent of the balloon to obtain high-accuracy and high-precision measurements. The implementation of controlled descent in a balloon sounding is quite a departure from traditional ballooning methods and has required the development and refinement of novel techniques. Here we describe two such techniques.

\subsection{Automatic valve technique}

The NOAA FPH has measured humidity profiles during ascent and controlled descent above Boulder since 1980 using a single balloon configuration similar to the traditional method. The only deviation from traditional ballooning is the addition of an automatic valve that releases helium gas from the balloon at a preset pressure, preventing balloon burst and inducing descent at a controlled rate similar to that of ascent $\left(\sim 5 \mathrm{~m} \mathrm{~s}^{-1}\right)$. The automatic valve has also been used successfully for monthly FPH soundings at Lauder, New Zealand, since 2004 and at Hilo, Hawaii, since 2010.

The automatic valve is of similar design to that built and employed by Mastenbrook (1966). That valve, first designed in 1964, consisted of a $14.6 \mathrm{~cm}$ ID Lucite (acrylic) ring with an internal aluminum disk sealed by gaskets and retained by a thin nylon string. The assembly was fit into the neck of a $7000 \mathrm{~g}$ neoprene balloon. A radiosonde baroswitch, pre-

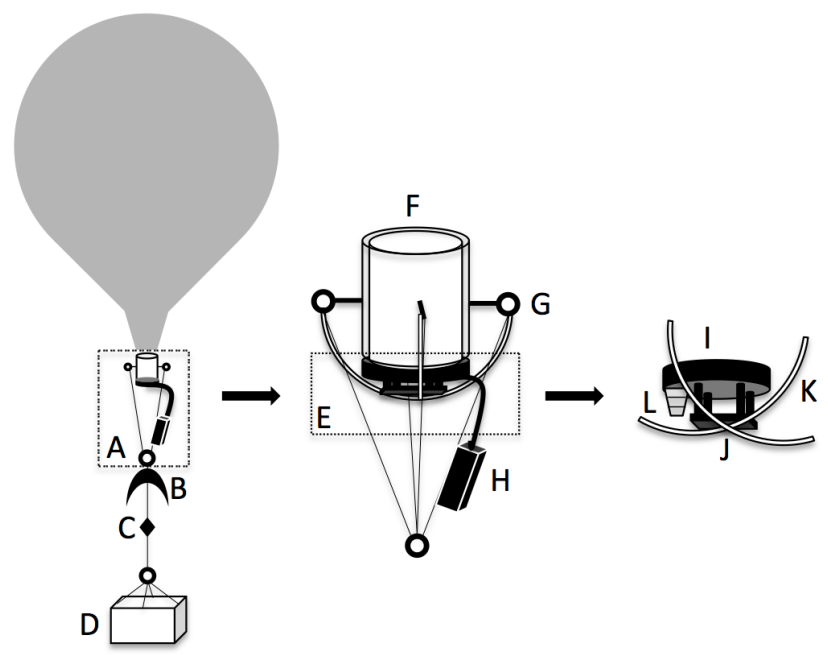

Figure 4. For the single balloon method of controlled descent the balloon flight train consists of (A) the automatic balloon valve and pressure sensor assemblies, (B) a parachute, (C) a $52 \mathrm{~m}$ string unwinder and (D) the instrument payload. The valve and pressure sensor assemblies include (E) a valve cap assembly, (F) a PVC pipe segment, $(\mathrm{G})$ four screw-in eyelets and $(\mathrm{H})$ a pressure sensor, logic board and batteries. The pipe cap assembly includes (I) a pipe cap, (J) a hot wire string cutter, (K) two cap anchoring strings and (L) a helium fill port.

set for the desired activation pressure, connected a $3 \mathrm{~V}$ battery to a short length of Nichrome wire to burn the retaining string. The aluminum disk would release from the Lucite ring, allowing helium to flow from the balloon. Over the years the valve materials have been changed from Lucite and aluminum to phenolic to PVC, for savings of both weight and cost, and the pressure sensor was modernized.

Today's valve consists of a $7.5 \mathrm{~cm}$ length of PVC pipe (9 $\mathrm{cm}$ OD , $4 \mathrm{~mm}$ wall), a pipe cap, two cap anchoring strings and a hot wire (Nichrome) string cutter (Fig. 4). The $175 \mathrm{~g}$ valve assembly is inserted into the balloon neck and tightly secured with a plastic cinch band. The string cutter is connected to a small pressure sensor, logic board and battery pack housed in small foam box (100 $\mathrm{g}$ total) anchored just below the balloon (Fig. 5). The logic board and pressure sensor are heated to $23^{\circ} \mathrm{C}$ to maintain the sensor's factory calibration. When the sensor measures ambient pressure lower than the preset threshold value the logic board sends current to a Nichrome wire bridge that burns through the cap anchoring strings. The cap falls away and helium flows out of the balloon through the uncapped pipe. Note that only helium is used to fill balloons outfitted with this valve because hydrogen would be ignited by the heated Nichrome wire. To date the heaviest payload successfully flown with this valve was approximately $5 \mathrm{~kg}$. Heavier payloads likely require larger balloons that often have larger necks that do not snugly fit the $9 \mathrm{~cm}$ OD pipe. When the valve opens and helium starts to flow, the balloon continues to ascend, slows until it reaches 


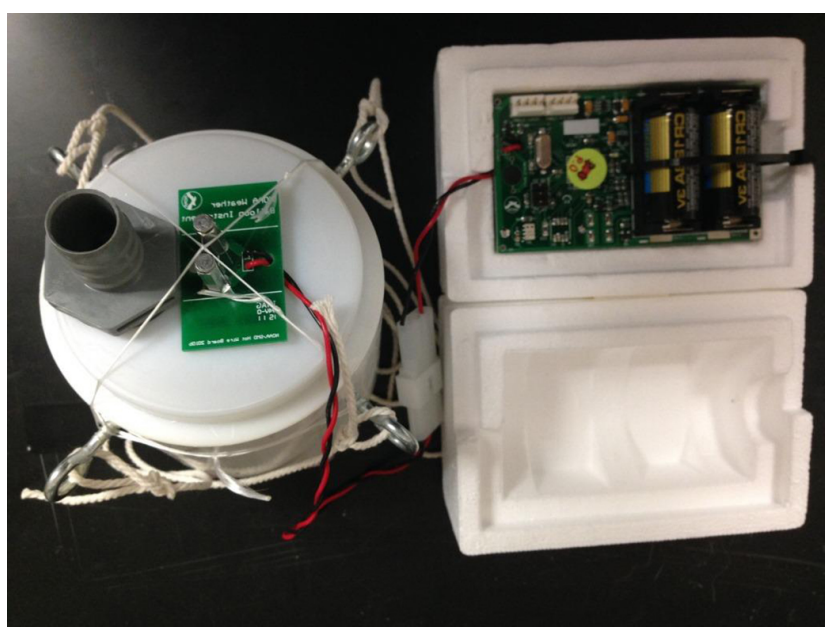

Figure 5. Automatic balloon valve (left) and pressure sensor assembly (right). Two thin strings anchoring the white circular pipe cap to the pipe are stretched across the hot wire string cutter. The foam box houses the pressure sensor, logic board and batteries. A cork is inserted in the gray helium fill port on the white pipe cap after the balloon is filled.

neutral buoyancy (float) then begins to descend as more helium is released. As the balloon descends the controlled rate slows from $5.4 \pm 0.4 \mathrm{~m} \mathrm{~s}^{-1}$ at $22-25 \mathrm{~km}$ to $3.1 \pm 0.3 \mathrm{~m} \mathrm{~s}^{-1}$ below $14 \mathrm{~km}$ (Fig. 1) for two reasons. First, the balloon's downward movement causes a ram air pressure to develop at the valve opening. Depending on the competing forces, this either restricts helium loss from the balloon or pushes air into the balloon, inflating it and increasing frictional drag. Second, as the balloon descends the internal gas is warmed by solar heating and the intake of warmer air, increasing its buoyancy. The greatest risk of failure for this method of controlled descent is an early burst before the valve opens. To keep this risk low, the pressure threshold is cautiously set to $16 \mathrm{hPa}(\sim 29 \mathrm{~km})$. Since 2008 controlled descents have been achieved for $\sim 75 \%$ of the about 250 balloons outfitted with a valve; most of the failures occurred because balloons burst prematurely. A parachute is employed in the flight train as a safeguard in case the balloon bursts (Fig. 4).

\subsection{Double balloon technique}

The double balloon technique uses a carrier balloon to lift the payload and a second smaller balloon that acts like a parachute once the carrier balloon is released. Each balloon is fixed to a vertex of a triangular frame of lightweight aluminum that connects them to the payload below (Fig. 6). The triangle is equipped with a release mechanism to cut the $20 \mathrm{~m}$ string of the carrier balloon at a preset altitude. An emergency parachute is fixed between the triangle and the parachute balloon in case the smaller balloon bursts. The large carrier balloon is inflated with enough hydrogen to lift the payload at $5 \mathrm{~m} \mathrm{~s}^{-1}$ during ascent while the smaller

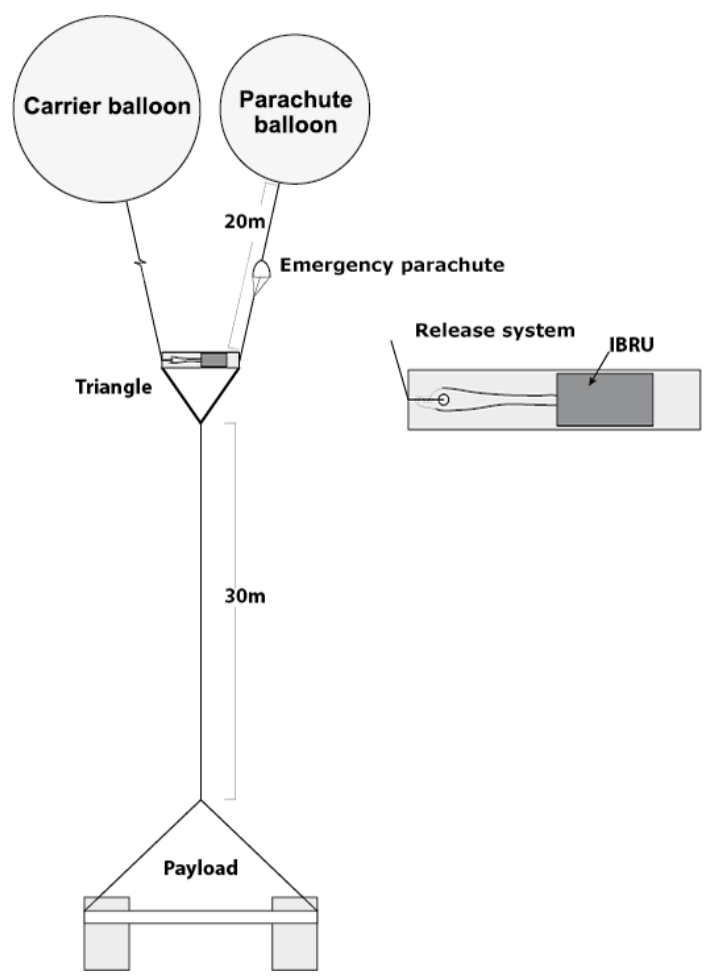

Figure 6. Double balloon sounding configuration with carrier and parachute balloon connected to the payload via the triangle that includes the IBRU release mechanism.

parachute balloon is inflated with enough helium to maintain a descent rate of $\sim 5 \mathrm{~m} \mathrm{~s}^{-1}$ once the carrier balloon is released.

The Intelligent Balloon Release Unit (IBRU) (Figs. 6 and 7) is housed in a rectangular Styrofoam box mounted on the horizontal triangle edge between the attachment rings of the two balloons. The IBRU system is based on a microcontroller that controls the GPS and the release mechanism for the carrier balloon. The tether string of the carrier balloon is attached to a bolt inside the release mechanism. In front of the bolt a tungsten wire is wrapped around the string. The hot wire which burns the tether string reaches temperatures of over $1000^{\circ} \mathrm{C}$ (red-hot). At the preset GPS altitude the IBRU burns the string, releasing the carrier balloon. Depending on how far apart the two balloons are, the carrier balloon release can be quite rough for the parachute balloon. The ideal situation is if they are only 2 to $3 \mathrm{~m}$ apart from each other. The initial descent velocity can reach up to $10 \mathrm{~m} \mathrm{~s}^{-1}$ but within a few seconds it slows down to the desired speed. At a descent altitude of $3000 \mathrm{~m}$ a.s.l. the IBRU switches on a mobile phone, finds a network and starts transmitting its coordinates via text message at regular intervals until the payload reaches the ground.

The launch process for the double balloon method has been improved over the last several years and is now comparable in effort to performing a regular radio sounding. Nev- 


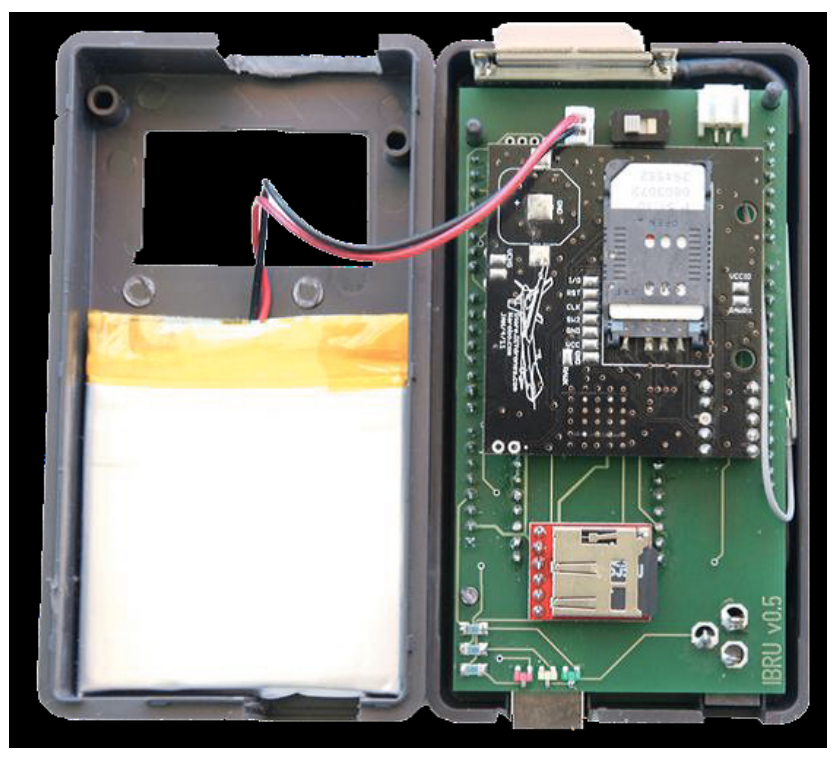

Figure 7. The IBRU consists of a microcontroller that controls the GPS, the release mechanism and a mobile phone to send text messages with the coordinates of the payload before landing.

ertheless, there are several different steps that require extra care. The gas amount for the two balloons is first determined in a spreadsheet, where the weights of all parts are summed and the correct gas amounts for $5 \mathrm{~m} \mathrm{~s}^{-1}$ ascent and descent are calculated. The two balloons are then filled as their lifting capacity is measured with a scale. The IBRU system is configured using a PC to set the release altitude and the mobile phone number. Once the balloons are filled they are attached to the triangle. The payload is then attached to the third vertex of the triangle and the entire flight train is lifted up and affixed to a launching pole prior to release (Fig. 8).

During ascent the two balloons have a tendency to separate, with the larger balloon leading. The triangle between the two balloons acts as a fix point stabilizing the payload. Comparisons have clearly shown that the pendulum motion usually observed on single balloon flights is strongly reduced with the double balloon technique. Figure 9 shows the horizontal travel of the payload over the first $2000 \mathrm{~m}$ of ascent during two simultaneous radiosonde flights, one using the traditional single balloon configuration (blue) and the other utilizing the double balloon (red) method. The two radiosondes travel in the same general direction but the single balloon payload moves in circles of up to $10 \mathrm{~m}$ radius due to pendulum motion while the double balloon payload does not. The reduced pendulum motion of the double balloon method is very important for radiation measurements where instruments need to remain as horizontal as possible during flight.

The double balloon method also improves the stability of descent rates compared to ascent rates. Two SRS-C34 radiosondes were flown together using a $1200 \mathrm{~g}$ carrier balloon and an $800 \mathrm{~g}$ parachute balloon. The IBRU was set to release

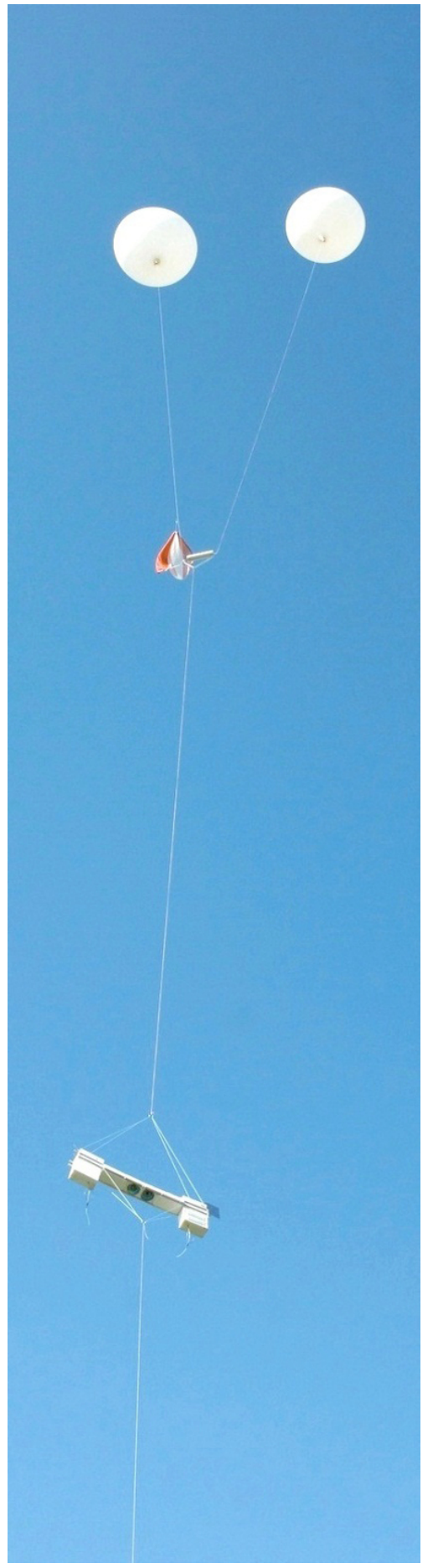

Figure 8. Flight configuration for the double balloon method. Each of the two balloons and payload are attached to a vertex of a triangular aluminium frame outfitted with the Intelligent Balloon Release Unit that releases the carrier balloon at a preset altitude. The configuration is shown attached to the launching pole just prior to release. 


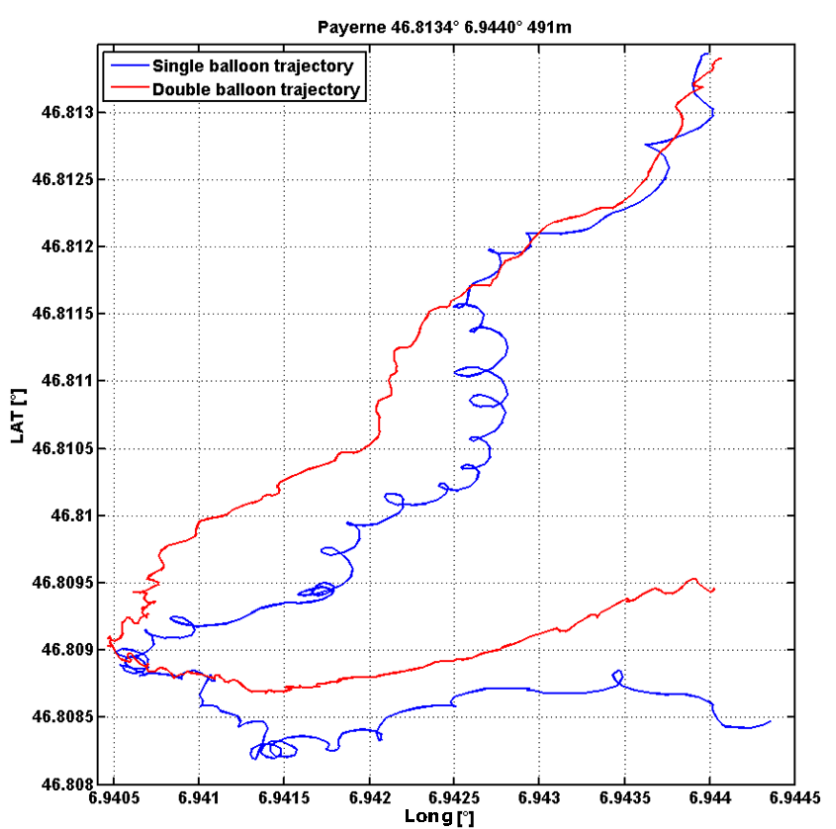

Figure 9. Horizontal trajectories of two radiosonde flights launched simultaneously at Payerne, Switzerland, on 12 May 2011. The two curves show the GPS latitude and longitude coordinates over the first $2000 \mathrm{~m}$ of ascent for the standard single balloon configuration (blue) and the double balloon configuration (red). Circles of up to $10 \mathrm{~m}$ radius in the single balloon radiosonde's trajectory show the pendulum motion of the payload that is absent in the double balloon radiosonde's trajectory.

the carrier balloon at $20 \mathrm{~km}$. Figure 10a shows the ascent and descent rates of the payloads as a function of altitude. The ascent rate averaged $5 \pm 0.8 \mathrm{~m} \mathrm{~s}^{-1}(1 \sigma)$, whereas the mean descent rate of $4 \pm 0.3 \mathrm{~m} \mathrm{~s}^{-1}$ was slightly slower but more consistent during the entire descent. Figure 10b shows the Doppler velocity, which is the instantaneous movement of the radiosonde measured by the GPS. During the descent the noise of the Doppler velocity is considerably lower, which demonstrates that the descent is more quiescent than the ascent despite double ballooning.

\section{Advantages and disadvantages of controlled balloon descent}

As described above the main advantage gained using controlled balloon descent for temperature and humidity measurements is the decreased potential for measurement contamination compared to ascent measurements. Double ballooning further strongly reduces the pendulum motion of the payload, an important factor for radiation measurements. It should be noted here that there are also some disadvantages when making measurements with certain types of instruments during controlled balloon descent.
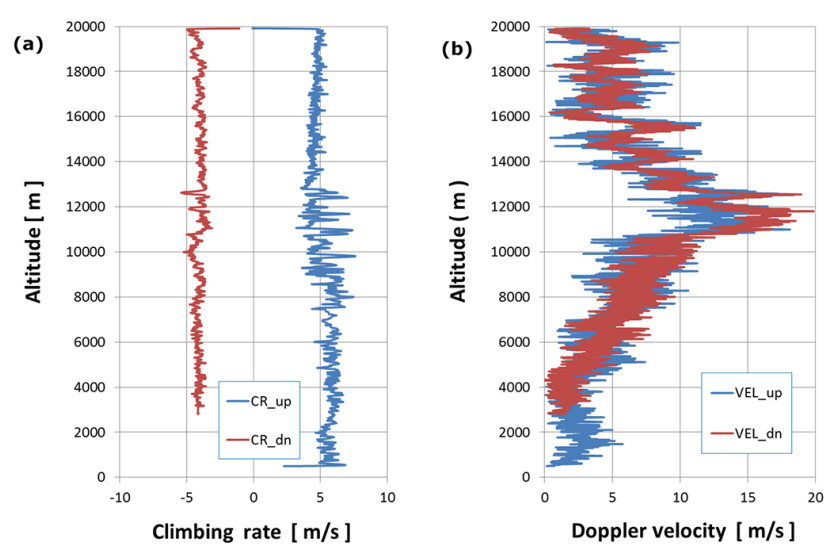

Figure 10. Double balloon flight to $20 \mathrm{~km}$ and back. Panel (a) shows the ascent and descent rates as functions of altitude. Panel (b) shows the Doppler velocity with considerably less noise during the descent than during the ascent, which demonstrates that for the double ballooning method, the descent is more quiescent than the ascent.

Some radiosonde sensors do not perform as well during descent because their orientations are optimized for best performance during ascent. There are three main factors for sensors that differ between ascent and descent: the direction and strength of ventilation flow past the sensor, the vertical structure of the parameter being measured and the vertical gradient of environmental parameters such as temperature. For example, some radiosondes have thin wire temperature sensors mounted on a sensor boom oriented to receive maximum ventilation flow towards the radiosonde during ascent. Reversing the direction of travel changes the direction of ventilation flow from the radiosonde package over the sensor boom towards the temperature sensor. During controlled descent these flow path differences are exacerbated by the weaker ventilation flow; the rapid descent after balloon burst would instead provide much stronger ventilation. Another example of a controlled descent disadvantage is that radiosonde capacitive polymer humidity sensors respond slowly to relative humidity (RH) changes when cold, so they perform better going from warmer to colder temperature environments (i.e., ascent through the troposphere).

Temperature measurements by International Met Systems iMet-1-RS radiosondes show distinct warm biases and additional noise during controlled descent compared to ascent (Fig. 11). Using an FPH flight at Boulder as an example, the iMet temperature measurements during controlled descent $\left(\sim 5 \mathrm{~m} \mathrm{~s}^{-1}\right)$ were warmer than ascent temperatures by an average of $1{ }^{\circ} \mathrm{C}$ from $18 \mathrm{~km}$ to the profile top at $28.1 \mathrm{~km}$ (Fig. 12). This bias and most of the variability in the ascentdescent temperature differences between 18 and $25 \mathrm{~km}$ are caused by the reversed ventilation flow during descent. If the descent temperature profile in Fig. 12 is used to calculate RH from the descent FPH measurements the warm temperature bias propagates a mean relative dry bias of $13 \%$ and triples 


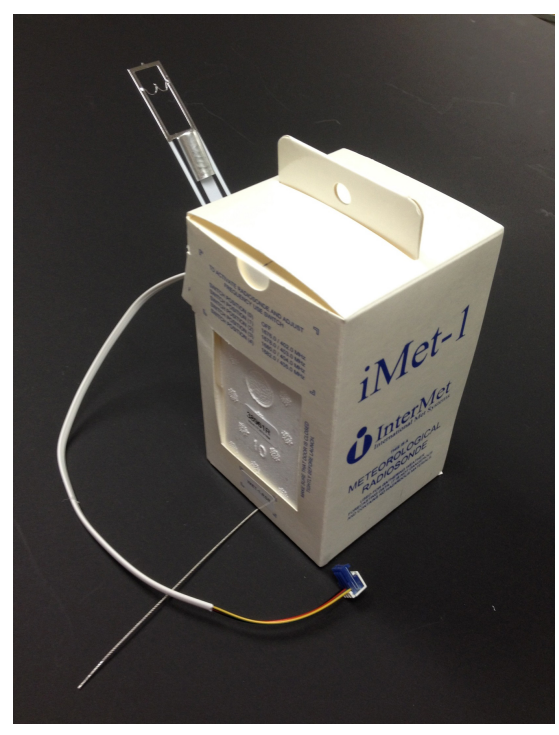

Figure 11. Intermet iMet-1-RS radiosonde used for FPH flights at Boulder.

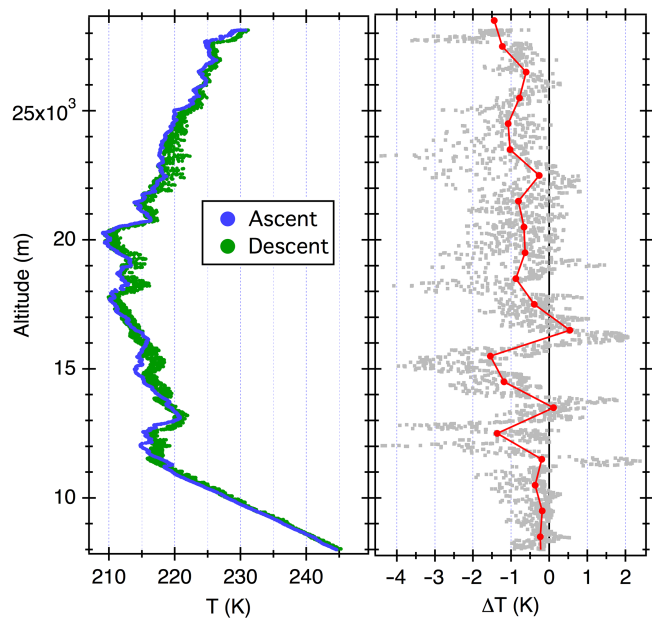

Figure 12. Ascent and descent temperature measurements by an iMet-1-RS radiosonde during a daytime balloon flight over Boulder (a). The descent measurements are biased warm and are noisier than the ascent measurements due to contamination by the reversed direction of sensor ventilation during descent. (b) Differences between the ascent and descent temperature measurements (gray) and the median ascent-descent differences within $1 \mathrm{~km}$ altitude bins (red) more clearly show the warm biases and increased noise during descent.

the noise in descent RH values. For these compelling reasons we selectively use ascent temperature profiles interpolated to descent altitudes to calculate descent RH values for FPH flights.

Another potential disadvantage of balloon flights with controlled descent is that payloads can travel more than twice the distance from the launch site compared to traditional burst flights. This, of course, depends on the strengths and di-

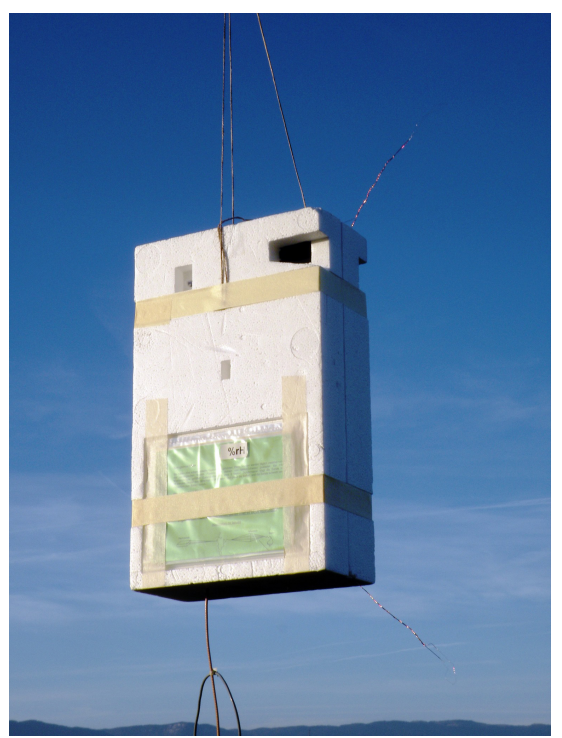

Figure 13. Meteolabor SRS-C34 radiosonde with original thermocouple temperature sensor fixed to thin wires that extend at a $45^{\circ}$ angle upward (above right) and an additional thermocouple temperature sensor at a $45^{\circ}$ angle downward (below right).

rections of winds during a flight, and is only a disadvantage if payload recovery is required. The reception of telemetry from radiosondes may also be curtailed prematurely during descent if the balloon travels a long distance from the launch site.

In contrast to most other radiosondes the thermocouple temperature sensor of the Meteolabor SRS-C34 radiosonde is not mounted in a sensor boom, but is fixed to thin wires that extend at a $45^{\circ}$ angle upward and is at least $100 \mathrm{~mm}$ away from the radiosonde (Fig. 13). Thus, the airflow around the radiosonde is not guided over the temperature sensor during the descent. According to the last World Meteorological Organization intercomparison, the uncertainty of SRS-C34 daytime temperature measurements is less than $0.2^{\circ} \mathrm{C}$ in the troposphere and about $0.4^{\circ} \mathrm{C}$ in the upper stratosphere (Nash et al., 2011). Figure 14a and b show ascent and descent temperature profiles of two SRS-C34 radiosondes flown about $2 \mathrm{~m}$ apart on a bamboo boom during the $20 \mathrm{~km}$ flight. The two panels show that ascent and descent profiles are very similar and that small temperature differences between them at about 5000, 13000 and $15500 \mathrm{~m}$ are measured by both radiosondes. The temperature differences measured between sonde 1 and sonde 2 are shown in Fig. 14c for the ascent and the descent. The temperature differences (descent minus ascent) presented in Fig. 14d show that both sondes measured similar differences at all altitudes for the $1000 \mathrm{~m}$ resolution (thick lines) as well as for the $100 \mathrm{~m}$ resolution (thin lines).

To check if the temperature sensors mounted above the radiosonde measure correctly during ascent and descent, the two radiosondes were equipped with additional temperature sensors fixed to thin wires extending downward from the 

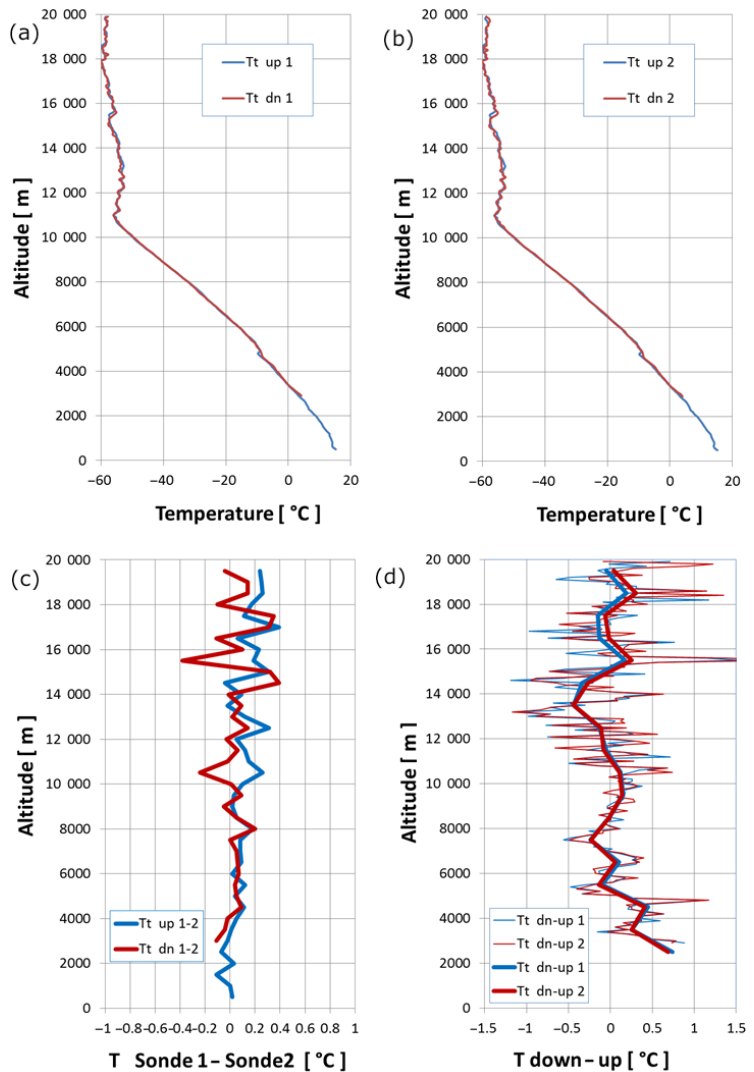

Figure 14. Temperature measurements by two SRS-C34 radiosondes during ascent to $20 \mathrm{~km}$ and controlled descent using standard temperature sensors $(\mathrm{Tt})$ mounted to the top of the radiosondes. Shown are (a) ascent and descent temperature profiles measured by sonde 1, (b) same as (a) but measured by sonde 2, (c) temperature differences between the two sondes and (d) descent-ascent temperature differences for each of the two sondes at vertical resolutions of $100 \mathrm{~m}$ (thin curves) and $1000 \mathrm{~m}$ (thick curves).

bottom of the radiosonde at a $45^{\circ}$ angle and $100 \mathrm{~mm}$ away from the box. Temperature measurements by the bottom sensors (Fig. 15) are very similar to those by the top sensors (Fig. 14). The two figures demonstrate that the $100 \mathrm{~m}$ resolution ascent-descent measurement disparities at particular locations $(5000,13000$ and $15500 \mathrm{~m})$ are real differences in the atmosphere. With the ascent starting around 10:00 local time on a more or less cloud-free day, the measurements show temperature profiles during ascent and descent that are within $0.4{ }^{\circ} \mathrm{C}(1000 \mathrm{~m}$ resolution), except around $13000 \mathrm{~m}$, where the atmosphere was apparently slightly colder during the descent. On the other hand slightly warmer temperatures were measured in the lower troposphere during descent, which is reasonable given the normal daytime temperature increase after 10:00 LT.
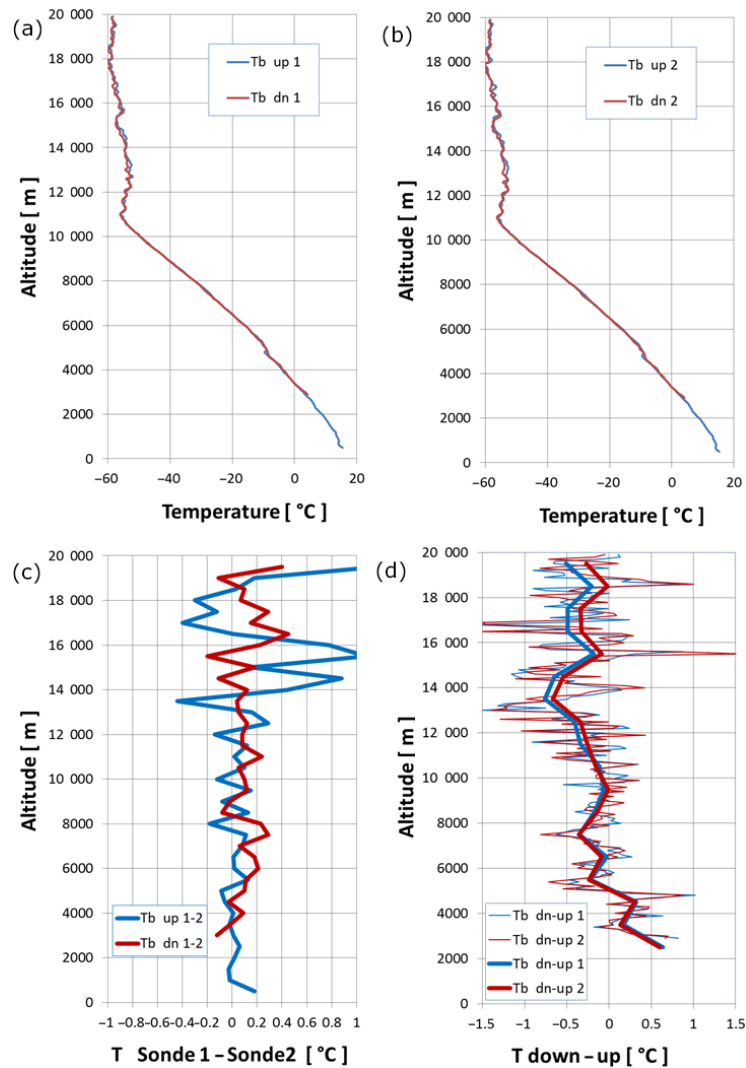

Figure 15. Temperature measurements by two SRS-C34 radiosondes during ascent to $20 \mathrm{~km}$ and controlled descent using additional temperature sensors $(\mathrm{Tb})$ mounted to the bottom of the radiosondes. Shown are (a) ascent and descent temperature profiles measured by sonde 1, (b) same as (a) but measured by sonde 2, (c) temperature differences between the two sondes and (d) descent-ascent temperature differences for each of the two sondes at vertical resolutions of $100 \mathrm{~m}$ (thin curves) and $1000 \mathrm{~m}$ (thick curves).

\section{Conclusions}

Controlled weather balloon ascents and descents are technically feasible and are needed primarily for atmospheric research and climate monitoring because they greatly reduce the potential of measurement contamination by the balloon and flight train, especially for measurements of temperature and water vapor in the UTLS. Controlled descent is also helpful for the proper filling of AirCore with whole air samples that are later analyzed to determine vertical profiles of atmospheric gases (Karion et al., 2010). Two different methods of achieving controlled descent have been described, both of which have been in use for years and tested for different purposes. Advantages and disadvantages are shown and technical descriptions are presented for the two nontraditional ballooning methods.

The most important advantage of controlled descent is that the air being measured is unperturbed by the balloon and flight train. The double balloon technique also strongly re- 
duces pendulum motion during ascent and allows smooth flights for radiation sensors or other instruments that require horizontal stability. A distinct disadvantage is that some radiosonde sensors, especially temperature sensors mounted on booms, are oriented optimally for ascent measurements, and therefore may be prone to additional noise and/or measurement biases during descent due to reversed sensor ventilation flow. Another potential disadvantage is that capacitive polymer RH sensors start their descent in an extremely cold environment where they respond slowly, but measurements during controlled descent are preferable to those during free fall in the stratosphere. Radiosondes with thin wire temperature sensors not mounted on sensor booms are much less sensitive to the direction of ventilation flow and are well-suited for measurements during balloon descent.

Acknowledgements. The authors would like to thank their colleagues for very valuable support during the preparation and launch phase of the different flights. As always, we appreciate the efforts of the anonymous reviewers whose comments helped improve this paper.

Edited by: H. Chen

\section{References}

Bodeker, G. E., Bojinski, S., Cimini, D., Dirksen, R. J., Haeffelin, M., Hannigan, J. W., Hurst, D. F., Leblanc, T., Madonna, F., Maturilli, M., Mikalsen, A. C., Philipona, R., Reale, T., Seidel, D. J., Tan, D. G. H., Thorne, P. W., Vömel, H., and Wang, J.: Reference Upper-Air Observations for Climate: From Concept to Reality, B. Am. Meteorol. Soc., 97, 123-135, doi:10.1175/BAMS-D-14$00072.1,2016$.

Forster, P. M. F. and Shine, K. P.: Assessing the climate impact of trends in stratospheric water vapour, Geophys. Res. Lett., 29, 1086, doi:10.1029/2001GL013909, 2002.

GCOS-112: GCOS Reference Upper-Air Network (GRUAN): Justification, requirements, siting and instrumentation options, Technical Document 112, WMO TD No. 1379, 25 pp., https://www. wmo.int/pages/prog/gcos/Publications/gcos-112.pdf, 2007.

Hergesell, H.: Ballon-Aufstiege über dem freien Meere zur Erforschung der Temperatur und der Feuchtigkeitsverhältnisse sowie der Luftströmung bis zu sehr grossen Höhen der Atmosphäre, Beitr. Phys. frei. Atmos., 1, 200-204, 1906.

Hermite, G.: Exploration des hautes régions de l'atmosphère à l'aide de ballons non montés, pourvus d'enregistreurs automatiques, Compt. Rend. Séances Acad. Sci., Paris, 115, 862-864, 1892.

Hoinka, K. P.: The tropopause: discovery, definition and demarcation, Meteorol. Z., 6, 281-303, 1997.

Hurst, D. H., Oltmans, S. J., Vömel, H., Rosenlof, K. H., Davis, S. M., Ray, E. A., Hall, E. G., and Jordan, A. F.: Stratospheric water vapor trends over Boulder, Colorado: Analysis of the 30 year Boulder record, J. Geophys. Res., 116, D02306, doi:10.1029/2010JD015065, 2011.
Karion, A., Sweeney, C., Tans, P., and Newberger, T.: AirCore: An Innovative Atmospheric Sampling System, J. Atmos. Ocean. Tech., 27, 1839-1853, doi:10.1175/2010JTECHA1448.1, 2010.

Lykov, A., Khaykin, S., Yushkov, V., Korshunov, L., and Cocquerez, P.: Observations of water vapour on board long-duration super pressure balloon using flash-B Lyman-alpha hygrometer, Conference Paper, Proceedings of the 19th ESA Symposium on European Rocket and Balloon Programmes and Related Research, 7-11 June 2009, Bad Reichenhall, Germany, 159-164, 2009.

Mastenbrook, H. J.: A control system for ascent-descent soundings of the atmosphere, J. Appl. Meteorol., 5, 737-740, 1966.

Nash, J., Oakley, T., Vömel, H., and Li, W.: WMO Intercomparison of high quality radiosonde observing systems, Yangjiang, China, 12 July-3 August 2010, World Meteorological Organization Instruments and Observing Methods, Report IOM-107, WMO/TD-No. 1580, https://www.wmo.int/ pages/prog/www/IMOP/publications-IOM-series.html, 2011.

Philipona, R., Kräuchi, A., and Brocard, E.: Solar and thermal radiation profiles and radiative forcing measured through the atmosphere, Geophys. Res. Lett., 39, L13806, doi:10.1029/2012GL052087, 2012.

Randel, W. J., Wu, F., Vömel, H., Nedoluha, G. E., and Forster, P.: Decreases in stratospheric water vapor after 2001: Links to changes in the tropical tropopause and the Brewer-Dobson circulation, J. Geophys. Res., 111, D12312, doi:10.1029/2005JD006744, 2006.

Seidel, D. J., Berger, F. H., Immler, F., Sommer, M., Vömel, H., Diamond, H. J., Dykema, J., Goodrich, D., Murray, W., Peterson, T., Sisterson, D., Thorne, P., and Wang, J.: Reference upper-air observations for climate: Rationale, progress, and plans, B. Am. Meteorol. Soc., 90, 361-369, doi:10.1175/2008BAMS2540.1, 2009.

Shimizu, K. and Hasebe, F.: Fast-response high-resolution temperature sonde aimed at contamination-free profile observations, Atmos. Meas. Tech., 3, 1673-1681, doi:10.5194/amt-3-1673-2010, 2010.

Solomon, S., Rosenlof, K. H., Portmann, R. W., Daniel, J. S., Davis, S. M., Sanford, T. J., and Plattner, G. K.: Contributions of stratospheric water vapor to decadal changes in the rate of global warming, Science, 327, 1219-1223, 2010.

Teisserenc de Bort, L.: Variations de la température de l'air libre dans la zone comprise entre $8 \mathrm{~m}$ et $13 \mathrm{~km}$ d'altitude, Compt. Rend. Séances Acad. Sci., Paris, 134, 987-989, 1902.

Thorne, P. W., Parker, D. E., Christy, J. R., and Mears, C. A.: Uncertainties in climate trends - Lessons from upper-air temperature records, B. Am. Meteorol. Soc., 86, 1437-1442, doi:10.1175/BAMS-86-10-1437, 2005.

Tiefenau, H. K. E. and Gebbeken, A.: Influence of meteorological balloons on temperature measurements with radiosondes: Nighttime cooling and daylight heating, J. Atmos. Ocean. Tech., 6, 36-42, 1989.

Trenberth, K. E., Karl, T. R., and Spence, T. W.: The need for a systems approach to climate observations, B. Am. Meteorol. Soc., 1593-1602, doi:10.1175/BAMS-83-11-1593, 2002.

Vömel, H., Yushkov, V., Khaykin, S., Korshunov, L., Kyro, E., and Kivi, R.: Intercomparisons of stratospheric water vapor sensors: FLASH-B and NOAA/CMDL frost-point hygrometer, J. Atmos. Ocean. Tech., 24, 941-952, doi:10.1175/jtech2007.1, 2007. 